\title{
Caring for a Chronically III Child While Employed: A cross sectional study on the impact on the quality of life of Jordanian mothers
}

Huda Gharaibeh ( $\sim$ hudag@just.edu.jo )

Jordan University of Science and Technology https://orcid.org/0000-0001-5090-214X

Muntaha Gharaibeh

Jordan University of Science and Technology

\section{Research article}

Keywords: Quality of life, mothers, chronic illness, children

Posted Date: July 3rd, 2019

DOI: https://doi.org/10.21203/rs.2.10869/v1

License: (c) (i) This work is licensed under a Creative Commons Attribution 4.0 International License.

Read Full License 


\section{Abstract}

1. Abstract Background: The quality of life of working women who cares for a child with chronic illness is of interest to families and health care professionals, as balancing work-life and routines of daily life gets complex when a child is chronically ill. The purpose of the study was to examine the QOL of working and non-working mothers caring for children with a chronic illness in Jordan. Results: Data from 164 mothers who cared for children with chronic illness were collected between November 2015 and April 2016 for this descriptive comparative cross sectional study using The World Health Organization Quality of Life BREF (WHOQOL-BREF) tool and examined the physical, psychological, social relationships, and environment domains of their quality of life. The quality of life of working mothers was significantly lower than those of non-working mothers on all domains of WHOQOL-BREF. Mother's working status, monthly income, evaluation of their own health explained $41 \%$ of the variance; adjusted R2 was $0.41, \mathrm{~F}=$ $(22.17,157), \mathrm{P}<0.0001$ Conclusions: Social, family and employer support may help mothers overcome the challenges of caring for a child with a chronic illness and maintain good QOL. Key words: Quality of life, mothers, chronic illness, children

\section{Background}

Caring for a chronically ill child can significantly impact families, and can result in negative health consequences and poor quality of life (QOL) in caregivers. According to the National Caregiver Alliance, one in six Americans care for someone with health problems while continuing their employment either full time or part-time (Family Caregiver Alliance, 2018). Family Caregiver Alliance also report that $70 \%$ of them experience work-related difficulties because of their dual role. About $75 \%$ of the caregivers are females and $14 \%$ care for their child with a chronic illness (Family Caregiver Alliance, 2018). Female workers may suffer from more economic hardship from caregiving due to alternate work arrangements or taking less paid jobs to fit the schedule (Family Caregiver Alliance, 2018). Therefore, they may choose to take additional jobs to meet their economic demands to cover the cost of caring (Family Caregiver Alliance, 2018). While this is in the context of the United States, similar statistics on caregivers are not available in the Middle Eastern/Arabic or Jordanian context.

Chronic illness in children affect the health and QOL of caregivers particularly that of the primary caregivers. Mothers are usually the primary caregivers consequences such as problems with adaptation, stress, depression, and hopelessness were reported in mothers (Delina \& Raya, 2013). This can affect their QOL, more significantly if the mother is employed (Vickers, Parris, \& Bailey, 2004). Examples of chronic conditions affecting children include inherited diseases, asthma, congenital heart diseases, cystic fibrosis, seizure disorders, and cerebral palsy, and each condition may have a unique impact on the caregivers.

\subsection{Literature Review}




\section{QOL definition}

Quality of life can be defined as "a state of complete physical, mental, and social well-being not merely an absence of disease ..." (WHO, 2019). QOL may be affected by the person's physical health, psychological state, personal beliefs, social relationships and their relationship to salient features of their environment (WHO, 2019).

\section{QOL of working women in general}

Quality of life of working and non-working women had been investigated in the past. Quality of work-life could determine the overall QOL of women (Bhola \& Nigade, 2014). Stevanovic and Rupert found that emotional exhaustion at work can result from family stressors and lack of family support (Stevanovic \& Rupert, 2009). Jackson (2013) that $78 \%$ of women felt they worked a 'second shift' when they try to fulfill the daily family responsibilities of doing tasks like laundry, cleaning, making dinner, and taking care of the family (Jackson, 2013). Drobnic and Rodriguez (2011) described this as a "double burden" hypothesis. The stress experienced by women who try to balance work and life on an ongoing basis may be aggravated when there is an additional responsibility of caring for a sick child at home.

\section{QOL of mothers who care for children with chronic illnesses}

QOL of mothers of healthy and sick children had been a topic of research for the past few decades. Croatian mothers of healthy preschool children reportedly have a better QOL if they are employed and they remain physically active (Babić, Humer \& Sincek, 2015). Cooklin et al., (2015) found that work-life balance may be important particularly in early years of parenting. Single mothers may be even more at a disadvantage (Dziak, Janzen \& Muhajarine, 2010). Mothers have reported "doing-it-all" while constantly being disappointed and challenged in their role of rearing a sick child (Vickers, Parris, and Bailey 2004). QOL of working mothers with healthy children may be different from the QOL of those who care for sick children. Caregiver burden and QOL of mothers who care for children with different types of chronic illness had been investigated. Poor QOL had been reported in caregivers of children with tracheostomy (Joseph et al., 2014), autism spectrum disorder (Cadman et al., 2012; Vohra et al., 2013; Miranda et al., 2015), sickle cell disease (van den Tweel et al., 2008), cerebral palsy (Marron et al, 2013) and brain damage (Chronister et al, 2016). Mothers who care for children with a chronic illness were found to have a higher level of anxiety and depression (Özkaya et al. 2010), and disrupted sleep patterns that can influence the mood, and, motor and cognitive functioning (Meltzer and Mindell 2006; van den Tweel et al. 2008). Maintaining the QOL of mothers is vital to meet the demands of her caring role, maintain her physical and mental health, and enable her to meet the physical and emotional needs of the ill child (Goldbeck 2006). The complexity of the situation increases when the mothers, with their additional tasks at home, try to fulfill their professional responsibilities. However, holding a job may be essential to meet their increasing financial demands. Financial instabilities secondary to missed work or leave of absences 
can affect their QOL (Lawoko, 2003). As women workforce increase globally it is essential to examine the status of Jordanian women who try to achieve work-life balance while caring for their sick child.

\section{Women workforce in Jordan}

While the status of women in Arabic culture is a topic of interest, Jordanian women have made significant achievements throughout the years such as higher school enrollment (98\%), marriage age of 26.7 years, and a life expectancy of 74.2 years (Jordan Statistical Report, 2016). Despite these achievements and the reduced gender gap in education, Jordan still has one of the world's lowest rates of working women at $17.7 \%$, a rate lower than the average women workforce in the Middle East (Jordan stats, 2016; The world bank data, 2019). Thus, due to low demand, services available for working women such as flexible working hours and availability of child care services are limited in Jordan.

Caregiving identity framework can be used to explain the processes involved in the complex caregiving situation (Montgomery, 2007; Talley \& Montgomery, 2013). Family obligations and role expectations in of females/mothers in Jordanian context endorses women as primary caregivers of children with chronic illness. Women are assumed to be gentle and caregiving in nature and nurture. This can physically and emotionally drain them and as the child grows on chronological age, their sense of loss of their dream child aggravates the emotional exhaustion. Educated women desires to have a career future and contribute to the society. They develop their identity as a professional-a teacher, nurse, etc., however, struggles to balance the caregiving role and professional role. In addition, the family may expect her to meet the regular needs of the family -care for household chores, care for parents, siblings and spouse. Mothers may try to negotiate the roles, seek support from family members, or even change jobs to accommodate the caregiving roles [Insert Figure 1 here]. Sometimes the context demands that they quit their jobs to meet the caregiving needs, placing additional financial burden on the family. Women should have the opportunity to remain in workforce while managing the day-to-day affairs of life and identifying the factors that impact their QOL is essential to develop strategies to support them to balance work, life and caregiving.

\section{Gap in literature and significance of the study}

Literature is scant on studies that examined the QOL of mothers -working or non-working-who care for a chronically ill child in the Jordanian context. The purpose of the study was to examine the difference in the perceived QOL of working and non-working mothers who care for children with a chronic illness. In addition, relationship between mothers' socio-demographic variables and QOL was examined. For purposes of this study the terms 'working women' was defined as women who work outside the home for a regular salary, and 'non-working women' was defined as the women who does not work for a regular salary. The caregiver identify framework will be used to examine the variables and the impact of employment on QOL of caregiving mothers. 
3. Hypotheses: We set the research hypotheses as:

1. The QOL of working mothers are significantly lower than that of the nonworking mothers who care for a chronically ill child.

2. The sociodemographic variables and perceived $\mathrm{QOL}$ and health are predictive of the QOL of mothers caring for a chronically ill child.

\section{Methods}

\section{$4 \& 5$ Design and Setting}

A descriptive comparative cross sectional design was used to conduct the study between November 2015 and April 2016 after obtaining approvals from the Institutional Review Boards (IRB) Jordan University of Science and Technology (JUST) (IRB \#1/74/2014) and the Ministry of Health, Jordan. Mothers were recruited at two public hospitals in the northern region of Jordan: a tertiary care teaching hospital, and a pediatric- affiliated teaching hospital with pediatric outpatient clinics.

\section{6 \& 10. Sample:}

Participation in the study was voluntary, participants provided oral and written consent, and confidentiality was assured. Inclusion criteria were as follows: mothers who care for children with a chronic illness; Jordanian nationality; and fluency in oral / written Arabic. They were informed about their right to withdraw from the study at any stage of data collection. Based on power Analysis (G*Power) a minimum of 143 participants were required for medium effect size of 0.3 , power as .80 , and predetermined alpha of .05 for a two tailed test (Cohen 1992). On recruitment 164 mothers agreed to participate (Response rate $=82 \%$ ).

\section{Variables:}

work-status of mothers, their demographic data, chronic illness in children,

\section{Measurements /Data collection tools}

Data were collected using two tools; a researcher-developed demographic data form (age, marital status, religion, education, occupation number of family members, and income), and the Arabic version of World Health Organization Quality of Life instrument WHOQOL- BREF (World.Health.Organization 1996), The WHOQOL-BREF consists of 26 items that includes two questions about the individual's overall perception of their own QOL and overall evaluation of their own health. The WHOQOL-BREF has four subscales depicting four domains: physical (7 items), psychological (6 items), social (3 items) and environmental (8 items). Each item is on a five- point Likert scale. The mean score of items within each domain is used to 
calculate the domain score. Guidelines for transforming the raw score of each item were used for calculating the mean score. Domain scores are scaled in a positive direction (i.e. higher scores denote higher QOL). The WHOQOL-BREF, a tool cross-culturally validated to measure QOL, has excellent psychometric properties (Skevington, Lotfy, and O'Connell 2004).

\section{Data Collection}

Mothers who agreed to participate were given a complete description of the study and they signed a consent form. Literate participants self- reported on the data collection form (Demographic and WHOQOL-BREF), while the researcher read the questions for mothers who were illiterate and recorded their responses in the form. All data were collected in hard copy forms and entered in SPSS 20.0. Incomplete or missed data were not encountered as the participants responded to all the items in the questionnaire. The hard copies of data were stored in a locked cabinet in the principal investigator's office.

\section{1 \& 12. Data analysis}

Descriptive analysis was used to define the sample characteristics. Independent sample $t$-test was usedto identify differences in QOL between working and non- working mothers. Linear regression analysis was used to predict factors influencing QOL of working mothers who care for children with a chronic illness. All assumptions for performing independent t-test on all domains of WHOQOL-BREF were met. Scores of all domains were normally distributed with accepted level of skewness between $(-0.44$ and -0.062$)$. A $p$ value of $<0.05$ level was considered statistically significant.

\section{Results}

\section{3. a. Demographic data}

Of the 164 mothers who participated in this study, 111 (67.7\%) were unemployed and $4.3 \%$ were illiterate (Table 1). The mean age of the participants was 33.8 years (range $16-56$ years). While $67 \% \%$ of the families had five or more family members in the household, only $24 \%$ of the families had an income more than 500 Jordanian Dinars (JOD). Complete data on sociodemographic variables of mothers are presented in Table 1.

[Insert table 1 here]

\section{716. Quality of life scores}

For the item on mother's perception of their overall QOL, significant difference was noted between the working and non-working mothers. On a scale of 1-5, working mothers reported a mean score of 2.79 (SD 
$=1.24)$ and non- working mothers reported a mean score of $3.35(\mathrm{SD}=0.09),(t=3.17, p=0.002)$. Similar results were noted on the mothers' evaluation of their own health with the mean score of working mothers being $M=2.77(S D=1.23)$, and that of non-working mothers being $M=3.43(S D=1.09),(t=3.46, p=0.001)$.

Independent samples $t$-tests was used to compare means to examine the difference between the two groups of mothers in each domain of the WHOQOL-BREF (Table 2). For all mothers, the highest mean score of the WHOQOL-BREF domains was reported for social relationship followed by physical health, then psychological domain, whereas the lowest score was reported for the environment domain. In all domains working mothers had lower scores than non-working mothers. In social relationship domain non-working mothers exhibited better scores (Working mothers: $M=57.86, S D=24.04$; non-working mothers: $M=66.06, S D=18.85 ; t=2.38 ; p=0.01)$. In the physical domain the Mean score of working mothers was $M=56.40$ ( $S D=16.06)$, while that of the non-working mothers was significantly higher, $M=62.87$ ( $S D=$ 13.78) $(t=2.66, p=0.009)$. This means non-working mothers were physically healthier and have better QOL compared to working mothers who care for children with a chronic illness. In the psychological domain also the non-working mothers had higher score indicating better QOL (Working mothers: $M=51.49, S D=16.23$; non-working mothers: $M=59.12, S D=16.23 ; t=2.66, p=0.009$ ), whereas no statistically significant difference was noted between the scores of the two groups in the environment domain (Working mothers: $M=48.34, S D=22.46$; non- working mothers: $M=54.47, S D=17.47 ; t=1.91$; $\mathrm{p}=0.057)$. Overall these scores indicate that non-working mothers had a better QOL than the working mothers (Table 2).

[Insert table 2 here]

\section{Risk Factors and Predictors of Quality of Life}

A multiple linear regression was performed to examine factors that could predict variance in mothers' QOL score. Six independent variables such as work status, evaluation of their own health, monthly income, education, age of the mother, and the number of family members, were used to perform regression analysis (Table 3 ). Three variables significantly contributed to the variance in the model. While work status of the mother $(\beta=-7.5, t=-3.59, P=0.001)$ was related to poor $Q O L$, perception of being in good health $(\beta=0.38, t=9.23, P=0.0001)$ and higher income $(\beta=0.005, t=1.90, P=.05)$ were significantly associated with improved WHOQOL-BREF scores. However, number of family members, mother's education, and mother's age did not significantly contribute to the variance (Table 3 ).

[Insert table 3 here]

\section{Discussion}

Hypotheses 1: The QOL of working mothers are significantly lower than that of the nonworking mothers who care for a chronically ill child. 
The findings of this study highlight the impact of caring for a sick child on the QOL of working mothers. The QOL of these mothers is important for their productive professional life, maintain their own social and emotional life, and deliver appropriate care to their sick children so that the child's health is maintained. Findings of the study lends support to the existing literature that working mothers caring for children with a chronic illnesses have lower QOL than non-working mothers. The majority of $m$ others in this study have children with respiratory problems such as asthma. Asthma has become the most serious chronic disease prevalent worldwide and Jordan is no exception. The rate of physician-diagnosed asthma in northern Jordan was $4.1 \%$, and wheezing was reported in $8.3 \%$ of primary school children (Abu-Ekteish, Otoom, and Shehabi 2009). Abu-Ekteish reported a two-fold increase of Asthma in Jordan in the previous decade. A systematic review including 50 studies on the prevalence of physician-diagnosed Asthma in the Middle-East was noted as 7.53\% (Mirzaei et al.2017). This predicts an increasing rate of Asthma affecting more families, particularly the mothers. Exacerbations in Asthma in the child may result in the mother's absenteeism from work, lower her financial potential, and poor life satisfaction from poor productivity, as well as emotional tension from having a sick child. While Sadeghifard et al., (2013) identified family functions, collaboration and power structure predictive of the QOL of women, they did not find any significant difference in the QOL scores of working and non-working women $(\mathrm{df}=260$; p.682). However, they identified healthier family functions exist among the working women $(p=0.005)$. It is understood that success of Asthma management is achieved by building on the family strength and resources (Crespo et al., 2011). Social and family support are essential for improving the QOL of these mothers.

Hypotheses 2: The sociodemographic variables and perceived QOL and health are predictive of the QOL of mothers caring for a chronically ill child.

Three variables in this study could predict the QOL of mothers: being a working mother, the mothers' evaluation of their QOL and general health, and monthly income. The mother's evaluation of perceived overall QOL and general health was 0.38 indicating a 0.38 increase in QOL scores for one-unit increase in mother's perception of her own QOL and the QOL of working mothers were 7.7 times lower than that of non-working mothers.

Overall lower WHOQOL-BREF scores may be the result of overwhelming responsibilities and a struggle to balance work and life. Current trend in Jordan to minimize inpatient hospital days and manage the sick child at home requires more involvement of mothers in the care of their children and may require time away from work thereby lowering the income (Guo et al. 2015, Koehler et al. 2014). Furthermore, families experience financial burden caused by the recurrent attacks of chronic illnesses requiring unpredictable emergency room visits (Koehler et al. 2014, Fagnano et al. 2012). This financial burden forces mothers to remain employed, while they may have to be absent form work or change jobs to meet the urgent care needs of the child.

With regard to the psychological domain working mothers reported lower mean score than the nonworking mothers. This aligns well with the findings of other researchers who reported that psychosocial 
determinants are more crucial in predicting parental QOL than medical and demographic variables (Hatzmann et al. 2009, Fidika, Salewski, \& Goldbeck 2013). In a systematic review on QOL of parents caring for children with Asthma involving 22 studies, Ekim and Ocakci (2016) found that providing higher level of care to child can be burdensome and have negative effect on the physical and psychosocial health of caregivers. The review supports the findings of this study that the QOL of caregivers is lower. The review identifies the importance of determining caregiver burden risks and protective factors so that interventional studies can be initiated to improve their QOL. Support for proper disease management and workplace strategy to support the mothers may be helpful in improving their QOL. In the meantime, healthcare professionals should pay structural attention to working mothers' functioning and wellbeing.

Application of the caregiver identity framework in this context tested the hypotheses and the burden of balancing job and caregiving beyond the routines of life may affect the QOL and health of mothers. The interconnectedness of the social, demographic, work-related and perception do of the mothers were predictive of the physical, emotional, social and environmental domains of QOL as measured by the WHOQOL-BREF.

\section{Limitations}

This study has several limitations. Not all mothers were literate; some mothers self-reported while others gave oral response which were transcribed. The comprehension of the questions might have varied due to the method of data collection. In addition, those mothers who were giving verbal response might have given responses that are socially acceptable. The level of understanding of the items in the tool by those who self- reported also might have been varied. The sample size was small; therefore, further studies to confirm the findings are essential prior to generalization.

\section{Interpretation and Implications for practice, education, research and policy}

Nurses can plan and implement care for children with chronic illnesses incorporating the social and psychological needs of the family. Special emphasis must be placed on the role of fathers in supporting the mothers in caring for their ill children, thus decreasing the burden of mothers. Until adequate support systems are available, health care professionals should acknowledge the mothers' feeling of 'caregiver burnout', so that support can be offered as the mothers try to balance their work and care for their sick children (Kidshealth, 2019). Emotional support, and, kind, compassionate and respite care can be offered while the child is receiving inpatient care. Health care professionals should be educated about the impact of sickness in their child on QOL of working mothers so that influencing factors can be addressed. Further research on specific factors in children with specific illnesses can help provide individualized support to the mothers. Research on interventions adaptable to the Jordanian context may lead to support programs for mothers who try to balance work and caregiving. "Working-mother-friendly' policies can help these mothers. Policies on paid and emergency leave, child care assistance, and reduced 
working hours can help these mothers alleviate their anxiety and improve their QOL. Public awareness on family support for caregiving and its impact on QOL of working mothers may help other family members to offer and provide support during crisis situations.

\section{Recommendation}

Workplace policies to accommodate the needs of working mothers who care for children with chronic illness must be developed. Policies should cover fathers of children with chronic illnesses as well, so that the fathers can support mothers, and may be able to take turns to care for their child. In addition, development of child care centers, which are capable of caring for children with chronic illnesses, near workplace, may help reduce absenteeism at work. Provision for Family Medical Leave of Absence (FMLA) can benefit such families as well.

\section{Conclusion}

Caring for a child with chronic illness is challenging to anyone, while this has a significant impact on the mothers who work. In the Arabic culture, mothers are the usual primary caregivers of children, particularly the sick ones. Mother's health and QOL has a direct impact on the health and QOL of the children who are sick. This study found that the QOL of working mothers who cared for children with a chronic illness is lower than that of non-working mothers. Family income, mothers' evaluation of their own health, and mother's work status are factors that significantly influenced their QOL. More services and support are essential for working mothers caring for children with chronic illnesses. These services may include child care services, flexible working hours, and psychological support, as well as decreasing their workload.

\section{Abbreviations Used:}

- QOL: Quality of Life

- WHO: World Health Organization

- WHOQOL-BREF: World health Organization Quality of Life (short instrument)

- JOD: Jordanian Dinar

- FMLA: Family Medical Leave of Absence

\section{Declarations:}

- Ethics approval and consent to participate: Institutional Review Board of King Abdulla Hospital, Irbid, Jordan, and approval from the Ministry of Health $(\mathrm{MOH})$, Jordan. The IRB number from King Abdulla hospital is $1 / 74 / 2014$. The approval from the Ministry of Health is a verification that the study can be facilitated in $\mathrm{MOH}$ institutions according to the IRB approval. 
Verbal and oral consents were obtained from participants. This was approved by the committee because of the literacy level of some participants.

- Consent for publication: Not applicable

- Availability of data and material

The datasets generated and/or analyzed during the current study are not publicly available as my IRB approval does not include that. But these are available from the corresponding author on reasonable request. The data is available with the principal investigator Dr. Huda Gharaibeh. Competing interests: there is no financial and non-financial competing interests.

\section{Other information}

- Funding: This study did not receive any funding.

- Authors' contributions: 'HG' (75\% of work; Literature review, methods, analysis, discussion); 'MG' (25\% of the work; introduction, discussion, and conclusion). All authors have read and approved the manuscript.

- Acknowledgements: Rachel Joseph, PhD, CCRN, Fulbright Scholar to Jordan University of Science and Technology, for her support and reorganization of the manuscript.

- Figure legends: NA

\section{References}

Abu-Ekteish, Faisal, Sameer Otoom, and Iman Shehabi. 2009. "Prevalence of asthma in Jordan: comparison between Bedouins and urban schoolchildren using the International Study of Asthma and Allergies in Childhood phase III protocol." Allergy and asthma proceedings.

Babić A, Humer JT, Sincek D. Physical Activity and Quality of Life of Mothers of Preschool Children. Coll Antropol. 2015 Jun;39(2

Bhola, S. S., \& Nigade, J. J. (2015). Impact of Worklife balance on healthof Women. In National Conference Emerging Drift.

Cadman T, Eklund H, Howley D, Hayward H, Clarke H, Findon J, Xenitidis K, Murphy D, Asherson P, Glaser K. (2012). Caregiver burden as people with autism spectrum disorder and attention-deficit/hyperactivity disorder transition into adolescence and adulthood in the United Kingdom. Am Acad Child Adolesc Psychiatry. 51(9):879-88. doi: 10.1016/j.jaac.2012.06.017. Epub 2012 Aug 2

Chronister, J., Johnson, E. T., Chan, F., Tu, W., Y., Lee, G. K. (2016). Positive person-environment factors as mediators of the relationship between perceived burden and quality of life of caregivers for individuals with traumatic brain injuries. Rehabilitation Counseling Bulletin, 59(4) $235-246$ 
Cohen, Jacob. 1992. "A power primer." Psychological bulletin 112 (1):155.

Cooklin AR, Westrupp E, Strazdins L, Giallo R, Martin A, Nicholson JM. Mothers' work-family conflict and enrichment: associations with parenting quality and couple relationship. Child Care Health Dev. 2015 Mar;41(2):266-77. doi:10.1111/cch.12137. Epub 2014 Mar 27. PubMed PMID: 24673505; PubMed Central PMCID:PMC4340039.

Crespo, C., Carona, C., Silva, N., Canavarro, M. C., \& Dattilio, F. (2011). Understanding the quality of life for parents and their children who have asthma: Family resources and challenges. Contemporary Family Therapy, 33, 179-196. DOI:10.1007/s10591-011-9155-5

Delina, G, and R Prabhakara Raya. 2013. "A study on work-life balance in working women." International Journal of Commerce, Business and Management 2 (5):274-282.

Dziak E, Janzen BL, Muhajarine N. 2010Inequalities in the psychological well-being of employed, single and partnered mothers: the role of psychosocial work quality and work-family conflict. Int J Equity Health. 9:6. doi:10.1186/1475-9276-9-6. PubMed PMID: 20175914; PubMed Central PMCID: PMC2837665

Ekim, A., \& Ocakci, A. F. (2016). iMedPub Journals Caregiver Burden in Pediatric Asthma: A Systematic Review Search strategy, 1-7. http://doi.org/10.21767/1791-809X.1000476

Fagnano, Maria, Emily Berkman, Elise Wiesenthal, Arlene Butz, and Jill S Halterman. 2012. "Depression among caregivers of children with asthma and its impact on communication with health care providers." Public health 126 (12):1051-1057.

Family caregiver Alliance. (n.d.). Caregiver Statistics: Demographics. Retrieved January 11, 2019, from https://www.caregiver.org/caregiver-statistics-work-and-caregiving

Fidika, Astrid, Christel Salewski, and Lutz Goldbeck. 2013. "Quality of life among parents of children with phenylketonuria (PKU)." Health and Quality of life outcomes 11 (1):54.

Goldbeck, Lutz. 2006. "The impact of newly diagnosed chronic paediatric conditions on parental quality of life." Quality of life research 15 (7):1121-1131.

Guo, Miaolan, Guozhen Gao, Jinlan Guo, Litao Wen, and Liting Zeng. 2015. "Burden among caregivers for children with asthma: A mixed-method study in Guangzhou, China." International Journal of Nursing Sciences 2 (4):394-401.

Hatzmann, Janneke, Marlies J Valstar, Annet M Bosch, Frits A Wijburg, Hugo SA Heymans, and Martha A Grootenhuis. 2009. "Predicting health-related quality of life of parents of children with inherited metabolic diseases." Acta Paediatrica 98 (7):1205-1210.

Jackson, S. (2013). Daily Life Factors that Contribute to Women's Stress. Retrieved January 7, 2019, from https://www.workingmomsagainstguilt.com/daily-life-factors-that-contribute-to-womens-stress/ 
Jordan Statistical Report., 2016. Department of Statistics. https://www.usaid.gov/jordan/gender-equalitywomens-empowerment. Accessed Auguest $8^{\text {th }} .2018$.

Jordanian Women's Report on the occasion of the International Women's Day - Statistical Perspective (News -March 7, 2018). Accessed on January 11, 2019, from http://dosweb.dos.gov.jo/jordanianwomens-report-on-the-occasion-of-the-international-womens-day-statistical-perspective/

Joseph, R. A., Goodfellow, L. M., \& Simko, L. M. (2014). Parental quality of life: caring for an infant or toddler with a tracheostomy at home. Neonatal Network: NN, 33(2), 86-94. http://doi.org/10.1891/07300832.33.2.86

Kidshealth. (2019). Taking Care of You: Support for Caregivers. Retrieved January 11, 2019, from https://kidshealth.org/en/parents/caregivers.html

Koehler, Alana D, Maria Fagnano, Guillermo Montes, and Jill S Halterman. 2014. "Elevated burden for caregivers of children with persistent asthma and a developmental disability." Maternal and child health journal 18 (9):2080-2088.

The World Bank data. Labor force, female (2019). Accessed january 27, 2019 https://data.worldbank.org/indicator/SL.TLF.TOTL.FE.ZS

Lawoko, S, and Joaquim JF Soares. 2003. "Quality of life among parents of children with congenital heart disease, parents of children with other diseases and parents of healthy children." Quality of life research 12 (6):655-666.

Marron, E. A., \& Catalunya, U. O. De. (2013). Burden on Caregivers of Children with Cerebral Palsy: Predictors and Related Factors *, 767-777. http://doi.org/10.11144/Javeriana.UPSY12-3.bccc

Meltzer, Lisa J, and Jodi A Mindell. (2006). Impact of a child's chronic illness on maternal sleep and daytime functioning." Archives of Internal Medicine 166 (16):1749-1755.

Montgomery, R. J. V. (2007). Caregiver identity theory overview. Retrieved from https://www.researchgate.net/publication/265260328_Caregiver_Identity_Theory_Overview

Miranda, A., Tárraga, R., Fernández, M. I., Colomer, C., \& Pastor, G. (2015). Parenting Stress in

Mirzaei, M., Karimi, M., Beheshti, S., Mohammadi, M. (2017). Prevalence of asthma among Middle Eastern children: A systematic review. Med J Islam Repub Iran, (31)9. https://doi.org/10.18869/mjiri.31.9

Families of Children with Autism Spectrum Disorder and ADHD.

http://doi.org/10.1177/0014402915585479

Özkaya, E, M Cetin, Z Uğurad, and N Samancı. (2010). "Evaluation of family functioning and anxietydepression parameters in mothers of children with asthma." Allergologia et immunopathologia 38 (1):25- 
30.

Sadeghifard, M., Zarei E., Rafiee, N. (2013). Anticipating Quality of Life of Working Women and Housewives Based on Power Structure, Collaboration and Family Functions. Journal of Educational and Management Studies J. Educ. Manage. Stud., 3(3): 257-260, 2013

Skevington, Suzanne M, Mahmoud Lotfy, and Kathryn A O'Connell. (2004). "The World Health Organization's WHOQOL-BREF quality of life assessment: psychometric properties and results of the international field trial. A report from the WHOQOL group." Quality of life Research 13 (2):299-310.

Stevanovic, P., \& Rupert, P. A. (2009). Work-Family Spillover and Life Satisfaction Among Professional Psychologists. Professional Psychology Research and Practice, 40(1), 62-68.

Talley, R. C. \& Montgomery R. J.V. (2013). Caregiving: A developmental, lifelong perspective. In: Talley, R. D., Montgomery, R. J. V. (Ed). Caregiving across the life span: Research practice and policy. New York, NY: Springer; 2013. pp. 131-156.

Van den Tweel, Xandra W, Janneke Hatzmann, Elske Ensink, Johanna H van der Lee, Marjolein Peters, Karin Fijnvandraat, and Martha Grootenhuis. 2008. "Quality of life of female caregivers of children with sickle cell disease: a survey." haematologica 93 (4):588-593.

Vickers, Margaret, Melissa Parris, and Jeff Bailey. 2004. "Working mothers of children with chronic illness: Narratives of working and caring." Australian Journal of Early Childhood 29 (1):39.

Vohra, R., \& Sambamoorthi, U. (2013). Access to services, quality of care, and family impact for children with autism, other developmental disabilities, and other mental health conditions, (December).

http://doi.org/10.1177/1362361313512902

World.Health.Organization. 1996. WHOQOL-BREF: introduction, administration, scoring and generic version of the assessment: field trial version, December 1996. Geneva: World Health Organization.

World Health organization (WHO) (n. d.). Quality of life. Accessed January 10, 2019, https://www.who.int/healthinfo/survey/whoqol-qualityoflife/en/

\section{Tables}

Table 1: Socio-demographic Characteristics of Participated Mothers 


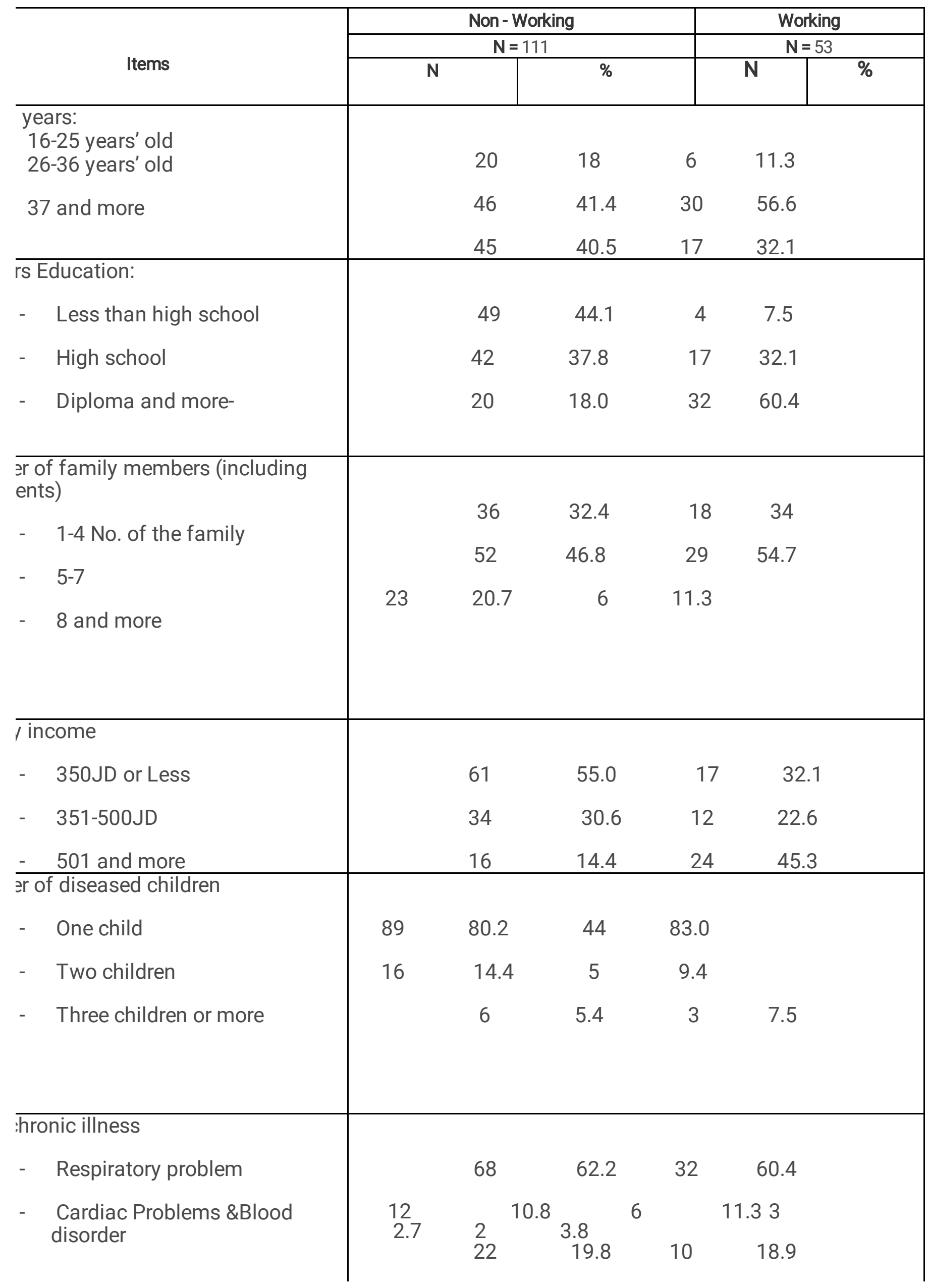


- Endocrine problem

- Neurological problem

- $\quad$ Gl problems \& others
4.5

5

5.7

Table 2: Results of independent $t$-test for differences in health-related quality of life between nonworking and working mothers

life subscales

Mean (SD)

Mean difference

$t$-value

$P$-value

Physical Health

Norking

$$
56.40(16.06)(13.78)
$$

6.46

2.66

.009

Psychological

\begin{tabular}{|c|c|c|}
\hline $\begin{array}{l}\text { Vorking } \\
\text { Norking } \\
\text { Social Relationship }\end{array}$ & $\begin{array}{l}59.12(16.23) \\
51.49(19.00)\end{array}$ & 7.62 \\
\hline $\begin{array}{l}\text { Vorking } \\
\text { Vorking } \\
\text { Envrionment }\end{array}$ & $\begin{array}{l}66.06(18.82) \\
57.86(24.04)\end{array}$ & 8.20 \\
\hline $\begin{array}{l}\text { Vorking } \\
\text { lorking } \\
\text { Jal's overall perception }\end{array}$ & $\begin{array}{l}54.47(17.35) \\
48.30(22.46)\end{array}$ & 6.12 \\
\hline $\begin{array}{l}\text { of life } \\
\text { orking } \\
\text { Jorking } \\
\text { tal's overall perception } \\
\text { alth }\end{array}$ & $\begin{array}{l}3.35(0.95) \\
2.79(1.24)\end{array}$ & 0.55 \\
\hline orking ${ }_{\text {Working }}$ & $3.43(1.09)$ & $\begin{array}{l}0.065 \\
(1.23)\end{array}$ \\
\hline
\end{tabular}


Table 3: Predictors of Health-related quality of life for working Mothers of children with chronic illness

\begin{tabular}{|c|c|c|c|c|c|}
\hline & B & SE & Beta & $t$ & $P$-value \\
\hline Jnstant & 49.35 & 4.95 & & 7.73 & $0.0001^{\star \star}$ \\
\hline orking mothers & -7.58 & 2.10 & -0.23 & -3.59 & $0.0001^{\star *}$ \\
\hline others evaluation of health & 0.38 & 0.04 & 0.57 & 9.23 & $0.0001 * *$ \\
\hline onthly income & 0.005 & 0.003 & 0.12 & 1.90 & $0.050 *$ \\
\hline others education & -2.91 & 2.16 & -0.09 & -1.34 & 0.18 \\
\hline ımber of family members & -0.40 & 0.48 & -0.05 & -0.83 & 0.40 \\
\hline other age & 0.02 & 0.126 & 0.01 & 0.17 & 0.86 \\
\hline
\end{tabular}

$R 2=0.414, R=0.64$. Predictors (constant): Working mother, Mothers' evaluation of health, Monthly income mother education, Numbers of family members, and mother age. Dependent variable: total quality of life.

\section{Figures}




\section{The Caregiver Identity Framework in the context of Working Mothers}

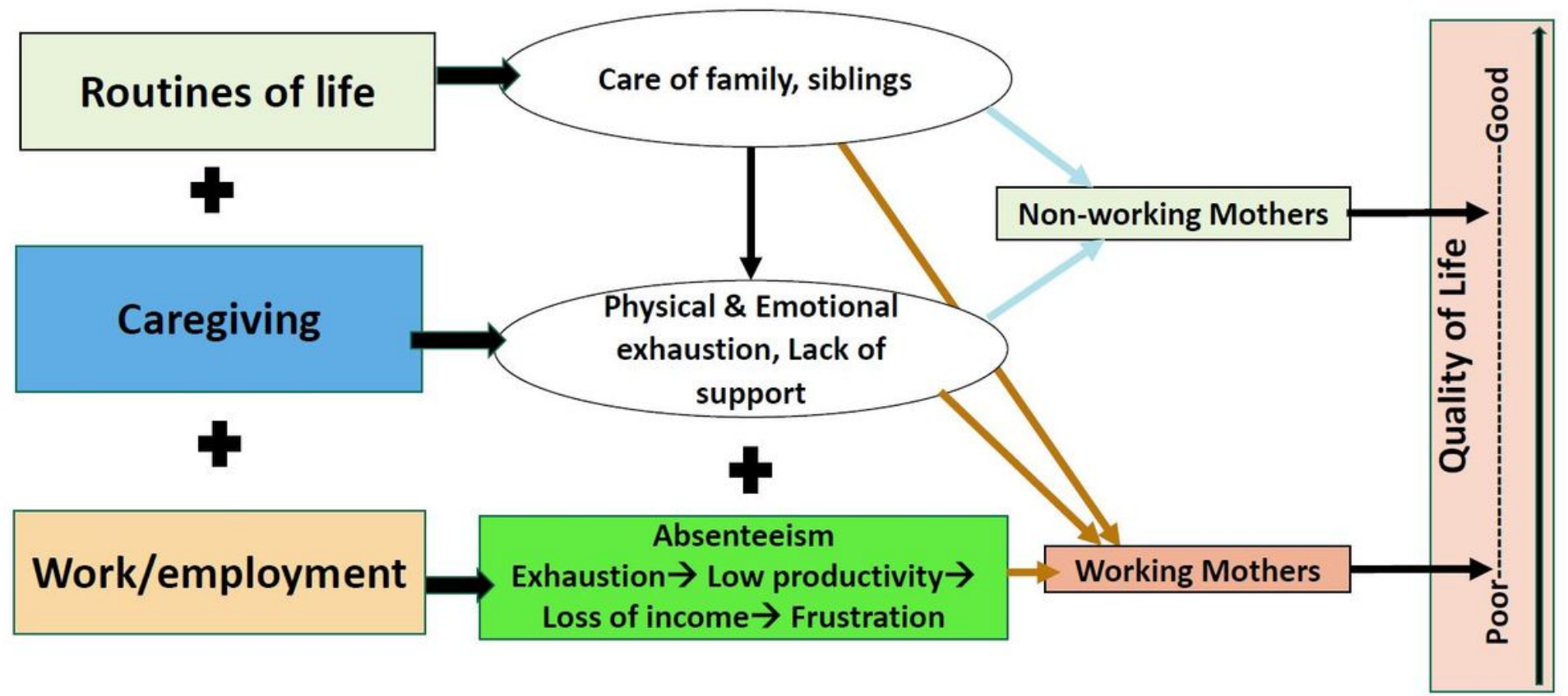

Figure 1

Caregiver Identify Framework in the context of working mothers.

\section{Supplementary Files}

This is a list of supplementary files associated with this preprint. Click to download.

- ISSMSTROBEChecklistJune102019.pdf 